\title{
Improved navigator based diffusion tensor MRI of the human heart in vivo
}

\author{
PF Ferreira ${ }^{1 *}$, S Nielles-Vallespin ${ }^{2,1}$, PD Gatehouse ${ }^{1}$, R de Silva ${ }^{1}$, J Keegan ${ }^{1}$, P Speier ${ }^{4}$, T Feiweier ${ }^{4}$, TG Reese ${ }^{3}$, \\ TF Ismail ${ }^{1}$, A Scott ${ }^{1}$, C Mekkaoui $^{3}$, DE Sosnovik ${ }^{3}$, D Firmin $^{1}$ \\ From 16th Annual SCMR Scientific Sessions \\ San Francisco, CA, USA. 31 January - 3 February 2013
}

\section{Background}

In vivo Cardiac Diffusion Tensor Imaging (cDTI) remains extremely challenging due to a mixture of cardiac and respiratory motion. In previous work a prospective navigator technique (NAV) has been implemented and compared to breath-hold (BH) acquisitions. Statistically significant differences were found between $\mathrm{BH}$ and NAV techniques for helix-angle (HA) values. Further interrogation of the data suggested that the inconsistent HA patterns were found in NAV data sets in which a small fraction (up to 10\%) of the diffusion-weighted frames had signal voids in some part of the LV. The purpose of this work was to improve the robustness of the NAV technique.

\section{Methods}

A stimulated-echo single-shot-EPI sequence was used, together with a modification of the crossed slice prospective-navigator technique combined with a biofeedback mechanism. To prevent bulk respiratory motion artefacts the first and second heartbeat have to be within $1 \mathrm{~mm}$ of each other as well as being inside the navigator acceptance window. 7 volunteers were scanned, with both $\mathrm{BH}$ and NAV techniques ( $b$ value $=350 \mathrm{~s} / \mathrm{mm} 2,8$ averages). Post-processing was enhanced by firstly adding an interface where bad frames where rejected, and secondly by using an image registration cross-correlation algorithm prior to averaging. The $\mathrm{cDTI}$ data was then processed to create fractional anisotropy (FA), mean diffusivity (MD) and HA maps in the myocardial region. A comparison of the $\mathrm{BH}$ data was then made between the two sets of NAV data: NAVold (without frame rejection and image registration) and NAVnew (with frame rejection and image registration). We specifically looked at the average myocardial FA and MD value, and the HA difference to a statistically averaged HA map from 10 healthy volunteers.

\section{Results}

A subject's averaged b0 image, FA, MD, and HA maps are shown in Figure 1. A paired t-test of the results of all volunteers between $\mathrm{BH}$ and NAVold shows significant difference in the mean FA ( $\mathrm{p}=0.014)$, and mean $\mathrm{MD}(\mathrm{p}=0.0036)$ but no significant difference in the mean HA difference maps $(\mathrm{p}=0.25)$. No statistical difference was found between $\mathrm{BH}$ and NAVnew: FA $(\mathrm{p}=0.14)$, $\mathrm{MD}(\mathrm{p}=0.074)$, and HA difference $(\mathrm{p}=0.21)$ (Figure 2).

\section{Conclusions}

Here we showed for the first time that a free-breathing navigator based approach to cDTI produces high quality in vivo images, comparable to that of the $\mathrm{BH}$ protocol. The ability to perform free breathing DTI will be critical if the use of DTI is to be extended to patients with cardiovascular disease and limited breath-hold capacity. This could prove to be a powerful tool to characterise the structural remodelling and fibre disarray patterns of diseases such as myocardial infarction and cardiomyopathies, improving the capability of cardiac MRI for diagnosis and therapy follow-up.

\section{Funding}

This work was supported by the NIHR Cardiovascular Biomedical Research Unit of Royal Brompton and Harefield NHS Foundation Trust and Imperial College London UK, and by the National Institutes of Health (grant: R01HL093038).

\footnotetext{
${ }^{1}$ Cardiovascular Biomedical Research Unit, Royal Brompton Hospital, London, UK

Full list of author information is available at the end of the article
}

(c) 2013 Ferreira et al; licensee BioMed Central Ltd. This is an Open Access article distributed under the terms of the Creative Commons Attribution License (http://creativecommons.org/licenses/by/2.0), which permits unrestricted use, distribution, and reproduction in any medium, provided the original work is properly cited. 

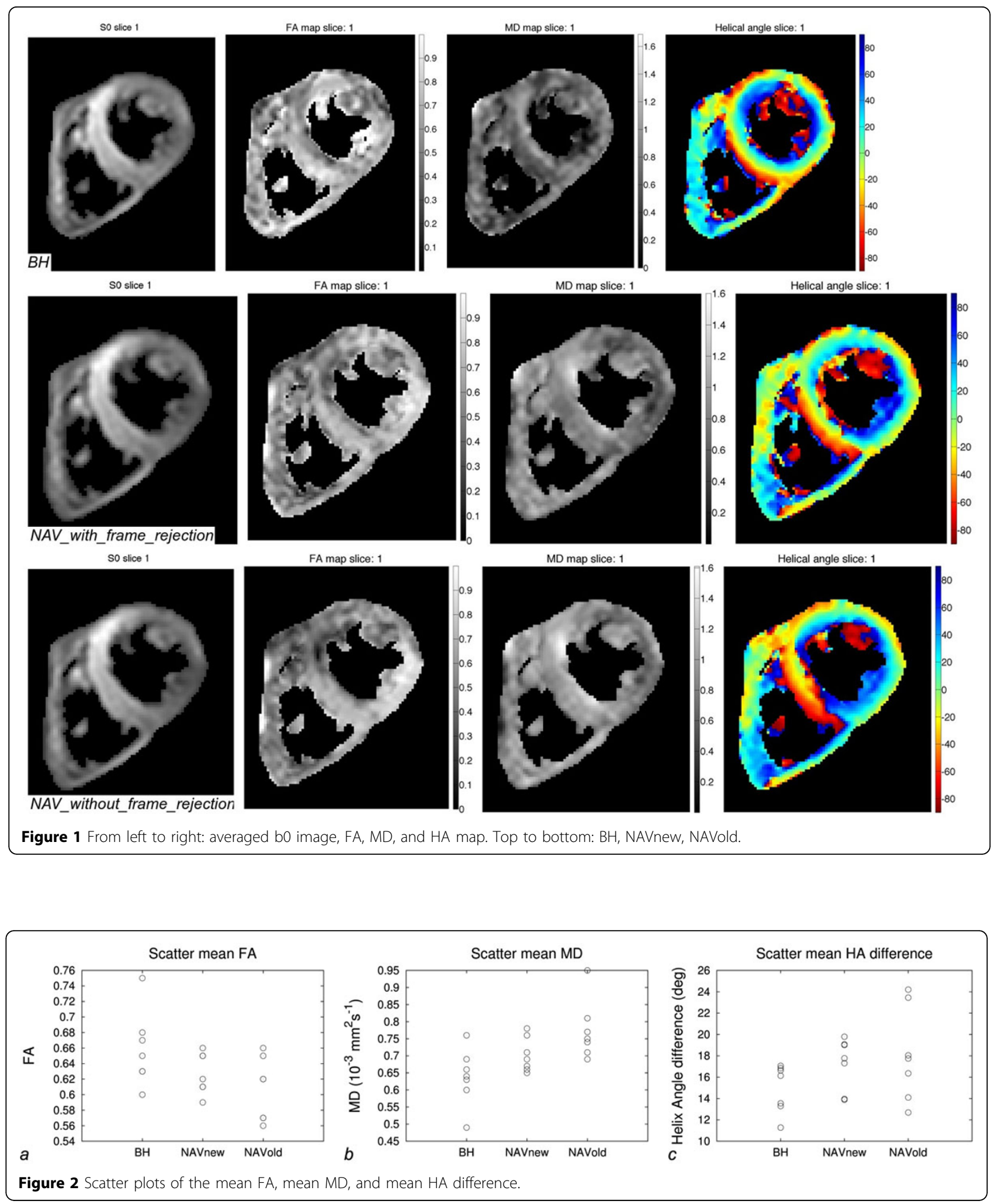


\section{Author details}

${ }^{1}$ Cardiovascular Biomedical Research Unit, Royal Brompton Hospital, London, UK. ${ }^{2}$ National Heart Lung and Blood Institute, National Institutes of Health , Bethesda, MD, USA. ${ }^{3}$ Martinos Center for Biomedical Imaging, Massachusetts General Hospital, Charlestown, MA, USA. ${ }^{4}$ MR Application \& Workflow Development, Siemens AG Healthcare Sector, Erlangen, Germany.

Published: 30 January 2013

doi:10.1186/1532-429X-15-S1-W25

Cite this article as: Ferreira et al:. Improved navigator based diffusion

tensor MRI of the human heart in vivo. Journal of Cardiovascular

Magnetic Resonance 2013 15(Suppl 1):W25.

Submit your next manuscript to BioMed Central and take full advantage of:

- Convenient online submission

- Thorough peer review

- No space constraints or color figure charges

- Immediate publication on acceptance

- Inclusion in PubMed, CAS, Scopus and Google Scholar

- Research which is freely available for redistribution

Submit your manuscript at www.biomedcentral.com/submit 